\title{
ARTIGOS
}

\author{
Submetido 12.08.2019. Aprovado 31.03.2021
}

Avaliado pelo sistema double blind review. Editor Científico: Marcus Gomes

Versão traduzida | DOI: http://dx.doi.org/10.1590/So034-759020220102X

\section{LICENÇAS DE EMISSÃO DE GASES DE EFEITO ESTUFA: TRANSPARÊNCIA DA INFORMAÇÃO FINANCEIRA}

\author{
Greenhouse gas emission allowances: financial reporting transparency \\ Derechos de emisión de gases de efecto invernadero: Transparencia de la información financiera
}

\author{
Patricia Milanés-Montero' ${ }^{1}$ | pmilanes@unex.es | ORCID: 00oo-0o01-7328-5519 \\ Esteban Pérez-Calderón ${ }^{1}$ | estperez@unex.es | ORCID: 0000-0002-4193-3769 \\ Ana Isabel Dias² | aidias@iscal.ipl.pt | ORCID: 0000-0002-6503-4792 \\ ${ }^{1}$ University of Extremadura, Faculty of Economics and Businnes, Badajoz, Espanha \\ ${ }^{2}$ Lisbon Polytechnic Institute, Lisbon Accounting and Business School, Lisboa, Portugal
}

\section{RESUMO}

Este estudo analisa a influência do comportamento das emissões de gases de efeito estufa no nível de transparência da informação financeira. Uma análise de conteúdo dos anexos às contas anuais das empresas permitiu medir seu nível de transparência. Os resultados sugerem que o nível de transparência da informação financeira está negativamente relacionado com o desempenho das emissões de gases de efeito estufa quando elaborado com base nas normas internacionais de relatório financeiro. Além disso, concluiu-se que essas empresas revelam mais "boas notícias" quando há baixo desempenho nas emissões de gases. Este estudo complementa a literatura anterior sobre a transparência da informação financeira e a necessidade de relacioná-la com medidas de ecoeficiência para melhorar a tomada de decisões dos usuários da informação. 0 estudo constitui igualmente uma referência para os órgãos reguladores contábeis europeus sobre o comportamento das empresas nesse domínio.

PALAVRAS-CHAVE | Emissões de gases de efeito estufa, norma internacional de relatório financeiro, relatório financeiro, dados em painel.

\section{ABSTRACT}

This research analyzes the influence that the performance of GHG emissions has on the level of transparency in financial reporting. Content analysis of the financial statement notes allowed the level of transparency to be measured. The results suggest that the level of transparency in financial reporting is negatively related to the performance of GHG emissions when financial reports are prepared on the basis of the International Financial Reporting Standards. It was also concluded that more 'good news' is disclosed by companies when their GHG emissions' performance reduces. This study complements previous literature about transparency in financial reporting, and the necessity to relate it to eco-efficiency measures to empower the decision-making process of stakeholders. The study also provides a reference for European accounting regulators on the behavior of companies with regard to this issue.

KEYWORDS I Greenhouse gas emissions, International Financial Reporting Standards, financial reporting, panel data.

\section{RESUMEN}

Esta investigación analiza la influencia que tiene el comportamiento de las emisiones de gases de efecto invernadero (GEI) en el nivel de transparencia de la información financiera. El análisis del contenido de las notas de los estados financieros de las compañías permitió medir el nivel de transparencia. Los resultados sugieren que el nivel de transparencia de la información financiera está negativamente relacionado con el desempeño de las emisiones de GEI cuando los informes financieros se preparan sobre la base de las Normas Internacionales de Información Financiera. Además, se llegó a la conclusión de que esas empresas revelan más "buenas noticias" cuando se reduce el rendimiento de las emisiones de gases. Este estudio complementa la literatura anterior sobre la transparencia de la información financiera y la necesidad de relacionarla con las medidas de ecoeficiencia para potenciar el proceso de toma de decisiones de los grupos de interés. Asimismo, el estudio proporciona una referencia para los reguladores contables europeos sobre el comportamiento de las empresas en esta materia.

PALABRAS CLAVE I Emisiones de gases de efecto invernadero, norma internacional de información financiera, información financiera, datos en panel. 


\section{INTRODUÇÃO}

A contabilidade de questões ambientais envolve dois tipos de informação para os stakeholders (Burritt, Schaltegger \& Zvezdov, 2011): por um lado, ela demonstra os impactos financeiros induzidos por questões ambientais e, por outro, os impactos físicos causados pela empresa no meio ambiente, o que pode resultar em uma relação de conflito e/ou dependência.

0 interesse nos impactos financeiros relacionados a questões ambientais aumentou na União Europeia (UE) após dois eventos (Llena, Moneva \& Hernandez, 2007): a Recomendação 2001/453 de 30 de maio sobre o reconhecimento, mensuração e evidenciação de informações ambientais em contas e relatórios anuais; e a implementação do Esquema de Comércio de Emissões da União Europeia (EU ETS). Ambos indicam que o comportamento ambiental deve ser evidenciado na contabilidade das empresas e/ou relatórios gerenciais, na medida em que possam influenciar a situação financeira.

No contexto do esquema de limites e comércio de emissões (cap-and-trade), há consenso na literatura de que as transações devem ser incluídas nos relatórios financeiros (Giner-Inchausti, 2014; Lovell, Bebbington, Larrinaga \& Aguiar, 2013; PWC \& IETA, 2007; Ragan \& Stagliano, 2007). 0 tratamento contábil das licenças de emissão (LEs) e das emissões de gases de efeito estufa (GEE) ganhou importância com o desenvolvimento de mercados regulados, como o EU ETS, pois podem ter uma influência significativa nas demonstrações financeiras, seja no que diz respeito à natureza das transações, ou em termos de valor (Mateos \& Bilbao, 2007; Warwick \& Ng, 2012).

Apesar da tão discutida materialidade das transações relacionadas ao EU ETS, as empresas vêm incorporando um tratamento contábil adaptado a sua natureza, o que permite comparações justas e transparentes entre as demonstrações financeiras (Giner-Inchausti, 2014) - considerando que sua não evidenciação pode resultar na apresentação de informações distorcidas (Ragan \& Staliano, 2007). Este estudo argumenta que a empresa deve ser transparente na evidenciação das transações relacionadas a sua participação no EU ETS em sua política contábil (Haupt \& Ismer, 2011) da mesma forma que o relatório financeiro tem conseguido fazer em relação a outras questões ambientais (Larrinaga, Carrasco, Correa, Llena \& Moneva, 2002; Ortas, Gallego-Álvarez \& Álvarez-Etxeberria, 2015).

Alguns órgãos reguladores reconhecem que os relatórios financeiros devem incorporar informações sobre transações envolvendo LEs e emissões de GEE, o que, a nosso ver, contribuiria para aumentar os níveis de transparência desses relatórios.

A influência do desempenho ambiental na evidenciação de informações da empresa sobre esse tema é frequentemente discutida na literatura, principalmente nos relatórios por ela emitidos voluntariamente (Cho \& Patten, 2007; Clarkson, Li, Richardson \& Vasvari, 2008; Liu, Zhou, Yang \& Hoepner, 2017; Milanés-Montero \& Pérez-Calderón, 2011; Patten, 2002). Considerando a crescente preocupação em incluir questões ambientais nos relatórios financeiros, Larrinaga et al. (2002) e Llena et al. (2007) sugeriram que tal prática não seria apenas uma resposta à regulamentação obrigatória, mas também uma forma de projetar uma imagem menos negativa para os stakeholders. Em relação ao EU ETS, esta imagem menos negativa pode ser proporcionada pela medição do desempenho das emissões de GEE, sugerida neste estudo como um elemento que influencia os níveis de transparência no relatório financeiro das questões ambientais. Esta pesquisa analisa a influência que o desempenho das emissões de GEE tem sobre o nível de transparência dos relatórios financeiros quando eles são preparados com base no International Financial Reporting Standards (IFRS) (Normas Internacionais de Relatórios Financeiros). A análise é desenvolvida levando-se em consideração o nível de informações sobre boas e más notícias evidenciadas pelas empresas em função do desempenho de suas emissões de GEE. A transparência nos relatórios 
financeiros está relacionada às medidas de ecoeficiência, dada a importância dessas informações nos processos de tomada de decisão dos stakeholders. 0 estudo se distingue de outros na literatura porque: (1) aborda a importância do nível de transparência em relação a LEs e emissões de GEE nos relatórios financeiros; e (2) estabelece uma relação entre uma medida de relatório financeiro ambiental e uma medida de desempenho ambiental, o que representa uma nova abordagem para a frequente associação entre esses elementos observada na literatura.

\section{REFERENCIAL TEÓRICO E DESENVOLVIMENTO DA HIPÓTESE}

\section{Relatório financeiro de LEs, emissões de GEE e questões de transparência}

Em 2005, o IASB lançou o IFRIC 3 ‘Direitos de Emissão’ para aplicação após o início da Fase I do EU ETS, mas apenas seis meses depois decidiu abortá-lo, argumentando que existia uma interpretação errônea da urgência da norma. A justificativa para essa medida, em consonância com o parecer negativo do European Financial Reporting Advisory Group (EFRAG), era que o tratamento contábil prescrito criava discrepâncias nas demonstrações financeiras. Tanto o EFRAG como uma extensa literatura anterior (Bebbington \& Larrinaga-González, 2008; Black, 2013; Ertimur, Francis , Gonzales \& Schipper, 2017; Giner-Inchausti, 2014; Lovell et al., 2013; MacKenzie, 2009; Steenkamp, Rahman \& Kashyap , 2011; Veith, Zimmermann \& Werner, 2009; Warwick \& Ng, 2012) apontaram que as discrepâncias introduzidas pelo IFRIC 3 ocorriam principalmente devido a uma medição discordante dos ativos (as LEs) e passivos (emissões de GEE), pois as LEs foram mensurados ao custo de amortização, ou valor de reavaliação, enquanto o passivo estava ao valor justo, o que resultaria em uma volatilidade artificial nos resultados reportados e não refletiria a realidade econômica das empresas.

A retirada do IFRIC 3 foi o início de uma ausência de normatização internacional de contabilidade, com consequências relacionadas ao uso de múltiplas práticas contábeis, conforme apontado em diversos estudos empíricos descritivos (Ayaz, 2017; Black, 2013; Lovell, Aguiar, Bebbington \& Larrinaga-Gonzales, 2010; PWC \& IETA, 2007; Warwick \& Ng, 2012). Apesar da posição do IASB, as autoridades reguladoras nacionais se sentiram impelidas a superar essa falta de orientação (Cuesta, Moneva \& Larrinaga, 2006).

A literatura anterior também concluiu uma alta ocorrência de não-evidenciação (Black, 2013; Lovell et al., 2010; PWC \& IETA, 2007; Warwick \& Ng, 2012). Esse fenômeno pode ser explicado por uma decisão profissional que interpretou as transações em um mercado baseado no sistema cap-and-trade como sendo materialmente relevantes (Busch \& Hoffman, 2001). Isso se deve ao sistema de isenções considerado nas Fases I, II e III do EU ETS para alocar LEs. Este sistema também justifica a adoção de políticas fora do balanço (Criado-Jiménez, Fernández-Chulián, Husillos-Carqués \& Larrinaga-González, 2008), embora Lovell et al. (2013) ameacem os fundamentos desta justificativa ao fornecer evidências da significativa materialidade das LEs.

Apesar de um certo ceticismo em relação à utilidade de impor o reconhecimento dessas transações (Giner-Inchausti, 2007), a multiplicidade de abordagens, incluindo o uso de políticas fora do balanço e de não evidenciação, revela a importância de um tratamento contábil comum que dê transparência ao comparar os relatórios financeiros de LEs e emissões de GEE (Giner-Inchausti, 2014; Lovell et al., 2010). Nesse sentido, ressaltamos que a característica qualitativa da relevância não se limita à materialidade, mas também inclui a natureza da relevância, que é útil quando se demonstram evidenciações importantes, principalmente em relação a questões ambientais. Além disso, embora a transparência não seja um princípio estabelecido nas estruturas conceituais, Barth e Schipper (2008) incluem essa perspectiva em seu conceito de transparência de relatórios financeiros. 
Com relação ao comportamento da empresa na evidenciação financeira de questões ambientais, Llena et al. (2007) concluíram que as empresas evidenciam menos 'más notícias', como provisões e contingências, do que 'boas notícias', como investimentos e despesas. Portanto, em um contexto de múltiplas abordagens, alcançar um maior nível de transparência para LEs recebidos gratuitamente, ou para o passivo em relação às emissões de GEE, pode não demandar relatórios obrigatórios - uma vez que essa maior transparência pode estar relacionada com a motivação da empresa em evidenciar sua atitude em relação ao EU ETS (Adams, Coutts \& Harte, 1995). Portanto, questionamos se o nível de transparência imposto nos relatórios financeiros pelas normas contábeis nacionais (com um tratamento obrigatório específico) é significativamente diferente do nível exigido na evidenciação baseada no IFRS, embora este último seja reconhecido como um conjunto de padrões financeiros da mais alta qualidade.

Com base no índice Wiseman, que destaca as consequências financeiras das atividades ambientais, Clarkson et al. (2008) concluíram que quando a exposição aos controles de emissão de GEE aumenta, as evidenciações obrigatórias em relatórios anuais e formulários 10-K também aumentam. Nos esquemas de evidenciação voluntária, a relação entre a evidenciação ambiental de uma empresa e seu desempenho nessa área tem sido frequentemente testada, mas, até onde se sabe, os estudos sobre relatórios financeiros são escassos. Na próxima seção desenvolvemos os argumentos sobre a influência do desempenho das emissões de GEE no nível de transparência dos relatórios financeiros, que servirão de base para formular nossa hipótese.

\section{Influência do desempenho das emissões de GEE no nível de transparência dos relatórios financeiros}

O EU ETS é um mecanismo baseado no mercado que visa controlar as emissões de GEE e tornar visíveis os custos dessas emissões. Esse tem sido um assunto polêmico, principalmente nos relatórios financeiros, conforme discutido na seção anterior. Os relatórios financeiros são uma forma de revelar aos stakeholders os riscos regulatórios e de mercado que influenciam as medidas de desempenho baseadas na contabilidade (Schiemann \& Sakhel, 2019).

Na literatura atual, o nível de transparência nos relatórios financeiros está frequentemente relacionado a) a fatores externos que são impostos às empresas, como regulamentos, por exemplo (Gallego-Álvarez, Martínez-Ferrero \& Cuadrado-Ballesteros, 2016; Giner-Inchausti, 1997; Veith et al., 2009), ou b) as próprias características da companhia como, por exemplo, seu desempenho ambiental no âmbito do EU ETS. Jaggi, Allini, Macchioni e Zagaria (2018) afirmam que é essencial que os investidores avaliem os riscos associados ao desempenho da empresa em relação a emissão de carbono, o que reforça a importância de uma maior transparência na evidenciação dessa informação, mesmo em países com sistema legal baseado em código civil. Estruturas conceituais para relatórios financeiros, que definem os fundamentos do IFRS, afirmam que a evidenciação financeira deve ser útil aos stakeholders, ou seja, deve existir alguma correspondência entre informações úteis e as medidas de desempenho das emissões de GEE, com a vantagem de se obter valor justo (observável), que o mecanismo de mercado atribui tanto às emissões de LEs quanto de GEE (Ascui \& Lovell, 2012). Lovell et al. (2013) também forneceram evidências de que a materialidade das LEs varia de $14 \%$ a $85 \%$ do lucro/prejuízo antes dos impostos, embora tenham reconhecido que não há cálculo óbvio para a contabilidade de carbono.

As políticas de evidenciação contábeis identificadas na literatura (Black, 2013; Lovell et al., 2010; Warwick \& Ng, 2012) podem ser reunidas em duas perspectivas (Larrinaga et al., 2002). Uma delas consiste em negligenciar aspectos da regulamentação que a empresa não deseja informar, adotando uma estratégia de dissimulação (Criado-Jiménez et al., 2008) e utilizando políticas de não evidenciação ou fora do balanço. Já no outro caso, 
empresas com melhores medidas de desempenho têm uma motivação para evidenciar mais informações, baseando-a em abordagens que fornecem dados relacionados, melhorando assim a sua transparência.

A literatura anterior concluiu que, em geral, não há associação significativa entre a evidenciação ambiental e o desempenho ambiental (Al-Tuwaijri, Christensen \& Hughes, 2004), mas estudos recentes (Qian \& Schaltegger, 2017) descobriram que uma mudança no nível de evidenciação de carbono motiva uma melhoria no desempenho em relação as emissões. Embora não tenham sido estudos causais e não possamos estabelecer uma relação "no sentido inverso", questionamos se há novas evidências de melhoria nos níveis de transparência em decorrência de comportamentos relacionados às emissões de GEE. Como há uma significativa lacuna de estudos empíricos anteriores que pudessem sustentar essa conexão, não temos a expectativa de observar desempenho na emissão de GEE ao examinarmos o seu nível de transparência. Para tanto, formulamos a seguinte hipótese não direcional:

H1: O nível de transparência dos relatórios financeiros de LEs e emissões de GEE não é influenciado pelo desempenho das emissões de GEE.

A seção a seguir apresenta nosso projeto de pesquisa empírica e a metodologia usada para testar a hipótese formulada.

\section{METODOLOGIA}

\section{Amostragem e dados}

Como fontes primárias, utilizamos os planos nacionais de alocação (PNAs), demonstrações financeiras anuais e o website da Comissão Europeia, junto com a documentação do Registro da União. 0 estudo analisa os efeitos do desempenho das emissões de GEE no nível de transparência dos relatórios financeiros, buscando diferenciar esses efeitos quando o relatório é preparado em base a normas contábeis nacionais (que preveem tratamento contábil explícito para LEs e emissões de GEE) e quando o relatório financeiro adota as diretrizes IFRS (que não possui orientação específica sobre esses aspectos). 0 estudo examinou empresas em Portugal, Espanha e França, uma vez que, nesses países, empresas negociadas em bolsa são obrigadas a produzir relatório de sua contabilidade de acordo com as normas do IFRS.

O período do estudo vai de 2008 a 2014, ou seja, todos os cinco anos da Fase II e os primeiros dois anos da Fase III do EU ETS. Não foi possível compilar as demonstrações financeiras anuais dos sete anos de 88 empresas, mas obtivemos inicialmente 559 observações, em um painel não balanceado.

Neste estudo, a análise de conteúdo das demonstrações financeiras de final de ano foi utilizada para avaliar as políticas contábeis adotadas em relação ao tratamento de LEs e emissões de GEE (Ayaz, 2017; Black, 2013; Steenkamp et al., 2011; Warwick \& Ng, 2012), visto que as contas anuais são a principal fonte de informação utilizada pelas práticas contábeis.

A análise de conteúdo tornou-se uma das formas mais comuns de análise de dados usada para fornecer conhecimento descritivo e compreensão de um determinado fenômeno que está sendo estudado. Entretanto, esse método é muitas vezes criticado por sua falta de rigor, a utilidade limitada de suas descobertas (Leung \& Chung, 2017) e por sua excessiva simplicidade - talvez seja por esses motivos que esse tipo de análise tenha sido pouco discutido na literatura. Ainda, dificuldades inesperadas podem surgir durante o processo de análise, uma vez que os autores muitas vezes veem o início da fase de categorização como caótico (já que nessa etapa 
possuem várias informações aparentemente desconexas), o material narrativo geralmente não é linear e os parágrafos de entrevistas transcritas podem conter elementos relativos a várias categorias. Para resolver essa situação, é preciso estar preparado para voltar aos dados e verificar a confiabilidade das categorias (Elo \& Kyngas, 2008).

Nesta pesquisa o uso dessa técnica de análise permitiu avaliar individualmente as políticas contábeis para reconhecimento e mensuração de LEs e emissões de GEE de forma desagregada, pois acreditava-se que isso responderia a algumas questões fundamentais. Essas políticas contábeis são resumidas por Elfrink e Ellison (2009) e EFRAG $(2012,2013)$ como aquelas que, até agora, têm sido discutidas por acadêmicos, reguladores nacionais europeus e empresas participantes ativas do EU ETS. Sem a análise exaustiva do conteúdo das notas anexas ao relatório, apresentadas no conjunto completo das demonstrações financeiras, um nível adequado de transparência não poderia ter sido alcançado.

As informações sobre as emissões de GEE foram obtidas no website do Registro da União, a fonte mais confiável de dados sobre as emissões de GEE alocadas e verificadas (Yu, 2013). O relatório Emissões Verificadas para 2014 foi utilizado para identificar os dados históricos de cada operador/ano desde 2008, os quais foram adicionados à respetiva empresa/ano de acordo com as práticas na literatura (Ertimur et al., 2009, 2017). A composição final da amostra foi um painel não balanceado de 85 empresas: 540 observações, 352 para relatórios financeiros baseados em IFRS e 188 para relatórios baseados em padrões nacionais.

\section{Variáveis}

Os índices de evidenciação (IEs) são autoconstruídos com base na análise de conteúdo das demonstrações financeiras anuais. As emissões de GEE foram recuperadas do Relatório de Emissões Verificadas de 2014, e os dados financeiros e econômicos foram retirados das demonstrações financeiras anuais e/ou do banco de dados Amadeus. 0 Quadro1 descreve as variáveis, suas respectivas medidas e as fontes.

\section{Variáveis dependentes}

Para medir o nível de transparência dos relatórios financeiros de LEs e emissões de GEE, os índices construídos são frequentemente aqueles que refletem aspectos relacionados às atividades ambientais (Liu et al., 2017; Matsumura, Prakash \& Vera-Muñoz, 2014; Patten , 2002; Steenkamp et al., 2011).

Os índices de evidenciação são a soma das respostas às questões colocadas na revisão da literatura, apoiadas nas políticas contábeis prescritas pelos reguladores nacionais em Portugal, Espanha e França (Black, 2013; Lovell et al., 2010; Warwick \& Ng, 2012). Para este trabalho, a análise de conteúdo das notas anexas ao relatório foi fundamental, pois nos permitiu identificar políticas contábeis individuais para LEs e emissões de GEE, que compilamos em oito itens de reconhecimento e medida: I1 Reconhecimento inicial dos LEs alocadas; I2 Contrapartida do reconhecimento inicial das LEs atribuídos; I3 Medição inicial de LEs; 44 Medição subsequente de LEs; 15 Reconhecimento de emissões de GEE; 16 Medição de emissões de GEE; I7 Reconhecimento de emissões de GEE superalocadas; e 18 Reconhecimento de LEs adquiridos para cobrir as emissões de GEE acima do limite. Cada um desses oito itens foi transformado em uma variável dummy que assume o valor 1 se alguma informação categórica foi evidenciada e o, nos casos de políticas de não evidenciação ou evidenciação fora do balanço. Essas últimas categorias são consideradas uma forma de reduzir os níveis de transparência nos relatórios financeiros de LEs e emissões de GEE. O IE é a soma das oito variáveis dummy (11 a I8), que assume o valor o se nenhuma política contábil foi evidenciada e o valor 8 se todas foram identificadas nas notas analisadas. 
Quadro 1. Definição das variáveis

\begin{tabular}{|c|c|c|c|c|}
\hline Variável & Tipo & Descrição & Medidas & Fontes \\
\hline IE & \multirow{3}{*}{$\begin{array}{l}\text { Variável dependente } \\
\text { (Nível de transparência) }\end{array}$} & Índice de Evidenciação & \multirow{3}{*}{$\begin{array}{l}\text { Valores de o a } 8 \\
\text { (soma das variáveis } \\
\text { dummy l1 a I8) }\end{array}$} & \multirow{9}{*}{$\begin{array}{l}\text { Notas } \\
\text { (Demonstrações } \\
\text { Financeiras Anuais) }\end{array}$} \\
\hline IE.IFRS & & $\begin{array}{l}\text { Índice de evidenciação } \\
\text { em uma base IFRS }\end{array}$ & & \\
\hline IE.GAAPN & & $\begin{array}{l}\text { Índice de evidenciação } \\
\text { em uma base GAAP } \\
\text { nacional }\end{array}$ & & \\
\hline IE.LE & \multirow{6}{*}{$\begin{array}{l}\text { Variável dependente } \\
\text { (Nível de transparência } \\
\text { - boas notícias x más } \\
\text { notícias) }\end{array}$} & $\begin{array}{l}\text { Índice de evidenciação } \\
\text { de boas notícias }\end{array}$ & \multirow{6}{*}{$\begin{array}{l}\text { Valores de o a } 4 \text { (é a } \\
\text { soma de I } 1 \text { a I } 4 \text { para LEs, } \\
\text { ou I5 a I8 para emissões } \\
\text { de GEE) }\end{array}$} & \\
\hline IE.eGEE & & $\begin{array}{l}\text { Índice de evidenciação } \\
\text { de más notícias }\end{array}$ & & \\
\hline IE.IFRS.LE & & $\begin{array}{l}\text { Îndice de evidenciação } \\
\text { de boas notícias no IFRS }\end{array}$ & & \\
\hline IE.IFRS.eGEE & & $\begin{array}{l}\text { Índice de evidenciação } \\
\text { de más notícias no IFRS }\end{array}$ & & \\
\hline IE.GAAPN.LE & & $\begin{array}{l}\text { Índice de evidenciação } \\
\text { de boas notícias em } \\
\text { GAAP nacional }\end{array}$ & & \\
\hline IE.GAAPN.eGEE & & $\begin{array}{l}\text { Índice de evidenciação } \\
\text { de más notícias em } \\
\text { GAAP nacional }\end{array}$ & & \\
\hline GEEeD & Variável explicativa & $\begin{array}{l}\text { Desempenho das } \\
\text { emissões de GEE }\end{array}$ & $\begin{array}{l}\text { Razão entre vendas } \\
\text { líquidas e emissões de } \\
\text { GEE } \\
\text { (em } € \text { por tonelada } \\
\text { métrica) }\end{array}$ & $\begin{array}{l}\text { Demonstrações } \\
\text { financeiras anuais } \\
\text { / banco de dados } \\
\text { Amadeus + Relatório de } \\
\text { emissões verificadas } \\
\text { para } 2014\end{array}$ \\
\hline Tam & \multirow{7}{*}{ Variáveis de controle } & Tamanho da empresa & $\begin{array}{l}\text { Logaritmo do ativo total } \\
(\mathrm{em} €)\end{array}$ & \multirow{6}{*}{$\begin{array}{l}\text { Demonstrações } \\
\text { financeiras anuais } \\
\text { / banco de dados } \\
\text { Amadeus }\end{array}$} \\
\hline ROA & & Retorno sobre ativos & $\begin{array}{l}\text { Razão do EBIT para o } \\
\text { total de ativos } \\
(\mathrm{em} €)\end{array}$ & \\
\hline ROE & & $\begin{array}{l}\text { Retorno sobre o } \\
\text { patrimônio líquido }\end{array}$ & $\begin{array}{l}\text { Razão entre o } \\
\text { rendimento líquido e o } \\
\text { capital próprio } \\
(\mathrm{em} €)\end{array}$ & \\
\hline ROS & & Resultado de vendas & $\begin{array}{l}\text { Razão entre as vendas } \\
\text { líquidas e os ativos } \\
\text { totais (em } € \text { ) }\end{array}$ & \\
\hline DebtE & & $\begin{array}{l}\text { Razão dívida/capital } \\
\text { próprio }\end{array}$ & $\begin{array}{l}\text { Proporção da dívida } \\
\text { total ao patrimônio } \\
\text { líquido (em €) }\end{array}$ & \\
\hline DebtTA & & Razão dívida/ativos & $\begin{array}{l}\text { Razão dívida total para } \\
\text { ativos totais (em } € \text { ) }\end{array}$ & \\
\hline Auditoria & & $\begin{array}{l}\text { Presença de relatório } \\
\text { de auditoria nas } \\
\text { demonstrações } \\
\text { financeiras anuais }\end{array}$ & $\begin{array}{l}\text { Variável dummy: valor } \\
1 \text { para contas com } \\
\text { relatório de auditoria, e } \\
\text { o caso contrário }\end{array}$ & $\begin{array}{l}\text { Demonstrações } \\
\text { Financeiras Anuais }\end{array}$ \\
\hline
\end{tabular}


A fim de distinguir o nível de transparência entre as normas segundo o IFRS e as GAAPs (conjunto de práticas contábeis nacionais), dois outros índices foram formulados: IE.IFRS que assume o valor o se nenhum dos oito itens forem evidenciados com base no IFRS, e 8 se todos forem; e IE.GAAPN que assume o valor o se nenhum dos oito itens forem evidenciados usando os GAAPs nacionais, e 8 se todos forem.

0 nível de transparência dos LEs e emissões de GEE também é avaliado por meio de "boas notícias" e “más notícias": IE.LE relacionado aos LEs (l1 a I4) é visto como "boas notícias"; e o IE.eGEE relacionado às emissões de GEE (15 a 18) é visto como “má notícia”. Outras quatro novas variáveis dependentes foram geradas a fim de diferenciar os níveis de transparência de "boas notícias" e "más notícias" em relação a cada base de relatório financeiro - IFRS e GAAP nacional: IE.IFRS.LE, IE.IFRS. eGEE, IE.GAAPN.LE, IE.GAAPN.eGEE, assume o valor o se nenhum dos quatro itens foi evidenciado e 4 se todos eles foram.

\section{Variáveis independentes: variáveis de tratamento e controle}

A razão entre as vendas líquidas e as emissões de GEE (valor das vendas para cada unidade de emissão de GEE) foi usada como medida do desempenho das emissões de GEE. Ehrenfeld (2005) chama de medida de ecoeficiência porque é a razão entre um valor econômico adicionado e uma medida de impacto ambiental. A literatura anterior (Busch \& Hoffman, 2011; Clarkson, Li, Pinnuck \& Richardson, 2015; Qian \& Schaltegger, 2017) usa a intensidade do carbono pela razão invertida do desempenho das emissões de GEE (emissões de GEE para valor econômico adicionado), que é reconhecida como uma medida de ecointensidade (Ehrenfeld, 2005). A taxa de desempenho das emissões de GEE foi transformada em um logaritmo para evitar parâmetros distorcidos, conforme a literatura (Busch \& Hoffman, 2011).

Com relação às variáveis de controle, espera-se que tamanho, lucratividade, risco financeiro e supervisão externa sejam apropriados para controlar o nível de transparência, pois representam as características da empresa que muitas vezes são utilizadas como fator explicativo para evidenciação (Gallego-Álvarez et al., 2016; Giner-Inchausti, 1997; Veith et al., 2009).

0 tamanho da empresa é considerado uma influência positiva na evidenciação de informações, uma vez que enfatiza que as grandes empresas são politicamente mais sensíveis e enfrentam pressões que entidades de menor porte não enfrentam. Clarkson et al. (2008), Prado-Lorenzo, Rodríguez-Domínguez, Gallego-Álvarez e García-Sánchez (2009), Matsumura et al. (2014), Luo, Lang e Tang (2012) concluem que as grandes empresas evidenciam mais informações relacionadas às suas emissões de GEE. Existem várias medidas que servem como proxy para o tamanho. Escolhemos o logaritmo dos ativos totais, como fizeram Giner-Inchausti (1997) e Gallego-Álvarez et al. (2016).

Medidas de lucratividade têm sido frequentemente utilizadas na literatura, porque empresas com melhor desempenho podem ser mais transparentes sobre suas atividades internas e, portanto, espera-se que entidades lucrativas apresentem mais evidenciações para justificar seu bom desempenho (Roberts, 1992). Vários estudos usam simultaneamente o retorno sobre os ativos (ROA) e o retorno sobre o patrimônio líquido (ROE) para controlar a lucratividade, uma vez que o ROA reflete o desempenho operacional e o ROE o desempenho financeiro (Giner-Inchausti, 1997; Prado-Lorenzo et al., 2009; Qiu, Shaukat \& Tharyan, 2016). Retorno sobre vendas (ROS) foi usado porque representa um retorno de curto prazo (Liu et al., 2017).

Os índices de alavancagem são usados para informar sobre os riscos de inadimplência que podem fazer com que o investimento e o financiamento sejam evitados. São também frequentemente usados como covenant, 
o que estimula os gestores a adotarem políticas contábeis que evitem um resultado inconveniente (Connors \& Gao, 2011; Prado-Lorenzo et al., 2009). Várias outras medidas podem ser encontradas na literatura, duas das quais foram incluídas neste estudo: a relação dívida/patrimônio líquido (Gallego-Álvarez et al., 2016; Ortas et al., 2015; Prado-Lorenzo et al., 2009), e a relação entre dívida e ativos (Busch \& Hoffman, 2011; Luo et al., 2012).

Um relatório de auditoria independente atesta a confiabilidade e relevância das práticas contábeis relacionadas às emissões de LEs e GEE, conferindo maior credibilidade às demonstrações financeiras (Dechow, Ge \& Schrand, 2010). Espera-se que a apresentação de um relatório de auditoria externa tenha um impacto positivo nos níveis de transparência. A variável 'auditoria' é uma variável dicotômica que assume o valor 1 se o relatório anual incorporar o relatório do auditor, e o se não incorporar.

\section{Modelo e análise econométrica}

Nosso modelo econométrico é diferente da literatura anterior na medida em que tenta avaliar o que leva uma empresa a evidenciar mais informações financeiras sobre a exposição às transações do EU ETS. Embora não possamos representar diretamente a estratégia não observável da empresa, podemos estimar a seguinte relação:

NivelTransparência ${ }_{\mathrm{it}}=\int\left(\right.$ desempenho das emissões de GEE, variáveis de controle) it $_{\mathrm{t}}$

A Equação 1 foi projetada para verificar a influência do desempenho das emissões de GEE no nível de transparência dos relatórios financeiros.

$$
N T_{i t}=\beta_{0}+\beta_{1} N T_{i t-1}+\beta_{2} G E E e D_{i t}+\emptyset X_{i t}+\varepsilon_{i t}
$$

Onde:

- i e t são respectivamente empresa e ano;

- NT representa as medidas para o nível de transparência: IE, IE.IFRS, IE.GAAPN, IE.LE, IE.eGEE, IE.IFRS.LE, IE.IFRS.eGEE, IE.GAAPN.LE, IE.GAAPN .eGEE;

- GEEeD é o logaritmo da razão entre as vendas líquidas e as emissões de GEE;

- X corresponde as variáveis de controle: Tamanho (Tam) é o logaritmo do ativo total; Rentabilidade: ROA, ROE e ROS; Alavancagem: relação dívida/patrimônio e relação dívida/total de ativos; Auditoria é uma variável dummy para a presença de relatório de auditoria independente;

- $\varepsilon$ é o termo de erro.

Para testar a Equação 1, empregamos uma técnica de regressão em dados em painel, que nos permite avaliar a transparência do relatório financeiro ao longo dos períodos, por meio da análise de observações de vários anos consecutivos para as mesmas empresas da amostra. Os modelos dinâmicos têm duas vantagens principais (Pindado \& Requejo, 2016): controlam a heterogeneidade não observada, ou seja, os efeitos individuais, como o julgamento profissional da gestão sobre relatórios financeiros, os níveis de transparência nos relatórios ou a consciência das emissões de GEE; e ajudam a mitigar o problema de endogeneidade que ocorre quando o termo de erro é correlacionado com qualquer uma das variáveis instrumentais. 0 estimador escolhido foi o sistema Método Generalizado de Momentos (MGM), de acordo com o modelo desenvolvido por Arellano e Bover (1995) e aplicado em estudos anteriores (Abrell, Ndoye, Zachmann, 2011; Yu, 2013). Apesar da escassa litera- 
tura sobre a relação em questão, temos consciência das relações causais no modelo proposto. Nesse sentido, a endogeneidade foi abordada por meio de variáveis instrumentais, que são mais comumente expressas como atrasos das variáveis endógenas (Labra \& Torrecillas, 2014). Como de costume na literatura do MGM, introduzimos a primeira defasagem da variável dependente como um regressor e as defasagens das variáveis explicativas e de controle como instrumentos. Esses valores defasados são candidatos naturais para instrumentos válidos porque podemos provar que eles não estão correlacionados com o termo de erro ao derivar o estimador. Eles também trazem informações sobre o valor atual da variável, pois frequentemente há um atraso entre a decisão tomada pelos indivíduos e sua efetiva realização (Labra \& Torrecillas, 2014). Arellano e Bond (1991) argumentam que usar mais instrumentos é uma forma de aumentar a eficiência, o que Pindado e Requejo (2016) concluem ser uma estratégia adequada para curtos períodos de tempo. Variáveis explicativas e de controle são consideradas variáveis endógenas. Para controlar a heterocedasticidade dos painéis incluímos a opção de robustez para determinar o desvio padrão do modelo, conforme sugerido por Windjmeier (2005).

\section{RESULTADOS}

A estatística resumida- demonstra que o nível de transparência aumentou no caso dos GAAPs nacionais e diminuiu para a base usando IFRS (ver Tabela 1).

Tabela 1. Estatística resumida e matriz de correlação

\begin{tabular}{|c|c|c|c|c|c|}
\hline Variável & Obs. & Média & Desvio Padrão & Min. & Max. \\
\hline$I E$ & 540 & 5,0037 & 2,8875 & 0 & 8 \\
\hline IE.IFRS & 352 & 4,7585 & 3,0450 & 0 & 8 \\
\hline IE.GAAPN & 188 & 5,4628 & 2,5107 & 0 & 8 \\
\hline IE.LE & 540 & 2,8000 & 1,6268 & 0 & 4 \\
\hline IE.eGEE & 540 & 2,2037 & 1,4682 & 0 & 4 \\
\hline IE.IFRS.LE & 352 & 2,6392 & 1,7040 & 0 & 4 \\
\hline IE.IFRS.eGEE & 352 & 2,1193 & 1,5238 & o & 4 \\
\hline IE.GAAPN.LE & 188 & 3,1011 & 1,4275 & 0 & 4 \\
\hline IE.GAAPN.eGEE & 188 & 2,3617 & 1,3472 & 0 & 4 \\
\hline GEEeD & 540 & 7,4819 & 2,1174 & 3,1761 & 14,4616 \\
\hline Tam & 540 & 19,5453 & 1,9484 & 14,4998 & 24,5375 \\
\hline$R O A$ & 540 & 0,0517 & 0,1197 & $-1,2022$ & 0,5791 \\
\hline$R O E$ & 540 & 0,1021 & 0,3392 & $-2,8407$ & 4,0087 \\
\hline ROS & 540 & 0,8227 & 0,5136 & 0,0082 & 3,0855 \\
\hline DebtE & 540 & 1,7876 & 3,2518 & $-28,0376$ & 33,1463 \\
\hline DebtA & 540 & 0,5549 & 0,2765 & $-1,1387$ & 1,5476 \\
\hline Auditoria & 540 & 0,8407 & 0,3663 & 0 & 1 \\
\hline
\end{tabular}


A matriz de correlação mostra que uma medida mais elevada de desempenho das emissões de GEE está negativamente associada aos níveis de transparência, embora o coeficiente indique que a redução não é significativa. Isso já era esperado, devido às questões de materialidade mencionadas acima (ver Tabela 2).

Tabela 2. Matriz de correlação de Spearman

\begin{tabular}{|c|c|c|c|c|c|c|c|c|c|c|c|c|c|c|c|c|c|}
\hline & 1) & 2) & 3) & 4) & 5) & 6) & 7) & 8) & 9) & 10) & 11) & 12) & 13) & 14) & 15) & 16) & 17) \\
\hline $\begin{array}{l}\text { 1) } \\
\mathrm{IE}\end{array}$ & 1 & & & & & & & & & & & & & & & & \\
\hline $\begin{array}{c}\text { 2) } \\
\text { IE.IFRS }\end{array}$ & $0,8417^{*}$ & 1 & & & & & & & & & & & & & & & \\
\hline $\begin{array}{c}\text { 3) } \\
\text { IE.GAAPN }\end{array}$ & $0,9526^{*}$ & $0,6839^{\star}$ & 1 & & & & & & & & & & & & & & \\
\hline $\begin{array}{l}\text { 4) } \\
\text { IE.LE }\end{array}$ & 1 & $0,9056^{*}$ & $0,9608^{*}$ & 1 & & & & & & & & & & & & & \\
\hline $\begin{array}{c}\text { 5) } \\
\text { IE.eGEE }\end{array}$ & $0,9056^{*}$ & $1,0000^{*}$ & $0,7923^{*}$ & $0,9056^{*}$ & 1 & & & & & & & & & & & & \\
\hline $\begin{array}{c}6) \\
\text { IE.IFRS.LE }\end{array}$ & $0,9608^{\star}$ & $0,7923^{*}$ & $1,0000^{*}$ & $0,9608^{\star}$ & * $0,7923^{*}$ & 1 & & & & & & & & & & & \\
\hline $\begin{array}{c}\text { 7) } \\
\text { IE.IFRS. } \\
\text { eGEE }\end{array}$ & 1 & $0,6121^{*}$ & $0,9440^{*}$ & -- & -. & -. & 1 & & & & & & & & & & \\
\hline $\begin{array}{c}8) \\
\text { IE.GAAPN. } \\
\text { LE }\end{array}$ & $0,6121^{*}$ & $1,0000^{*}$ & $0,3698^{\star}$ & -. & -. & .. & $0,6121^{\star}$ & 1 & & & & & & & & & \\
\hline $\begin{array}{c}9 \text { ) } \\
\text { IE.GAAPN. } \\
\text { eGEE }\end{array}$ & $0,9440^{*}$ & $0,3698^{*}$ & $1,0000^{*}$ & -. & -. & .. & $0,9440^{\star}$ & * $0,3698^{\star}$ & 1 & & & & & & & & \\
\hline $\begin{array}{c}\text { 10) } \\
\text { GEEeD }\end{array}$ & $-0,1940^{*}$ & $-0,1135^{*}$ & $-0,2089^{*}$ & $-0,1998^{\star}$ & $-0,1202^{\star \star}$ & $\star-0,2179^{\star}$ & $-0,2524^{*}$ & $-0,1058$ & $-0,2200^{*}$ & 1 & & & & & & & \\
\hline $\begin{array}{l}\text { 11) } \\
\text { Tam }\end{array}$ & $-0,0367$ & $-0,0589$ & $-0,0221$ & 0,0213 & 0,0717 & $-0,0002$ & $-0,2123^{*}$ & $-0,2931^{\star}$ & $-0,113$ & $-0,1744^{\star}$ & 1 & & & & & & \\
\hline $\begin{array}{l}\text { 12) } \\
\text { ROA }\end{array}$ & $0,1671^{*}$ & $0,1040^{\star \star}$ & $0,1728^{*}$ & $0,2560^{*}$ & $0,2004^{*}$ & $0,2701^{*}$ & " 0,0049 & $-0,1222^{\star \star \star}$ & $\star-0,0054$ & $0,3658^{\star}$ & $-0,0704$ & 1 & & & & & \\
\hline $\begin{array}{l}\text { 13) } \\
\text { ROE }\end{array}$ & $0,1098^{* \star}$ & 0,0228 & $0,1300^{*}$ & $0,1663^{*}$ & $0,1186^{\star \star}$ & * $0,1730^{\star}$ & 0,006 & $-0,2067^{\star}$ & 0,0536 & $0,2240^{\star}$ & $-0,0444$ & $0,6963^{\star}$ & 1 & & & & \\
\hline $\begin{array}{l}\text { 14) } \\
\text { ROS }\end{array}$ & $0,1427^{\star}$ & $0,1482^{*}$ & $0,1390^{*}$ & $0,1918^{\star}$ & $0,1901^{*}$ & $0,1787^{\star}$ & 0,0069 & $-0,0222$ & 0,0466 & $-0,0602$ & $-0,2407^{\star}$ & $0,1111^{*}$ & $-0,0074$ & 1 & & & \\
\hline $\begin{array}{c}\text { 15) } \\
\text { DebtE }\end{array}$ & $-0,0268$ & $-0,1252^{\star}$ & 0,0218 & $-0,0049$ & $-0,0898^{\star}$ & 0,0127 & $-0,1104$ & $-0,1970^{*}$ & 0,018 & $-0,0815^{\star \star \star}$ & $0,0963^{\star \star}$ & $-0,1296^{*}$ & 0,0185 & $-0,1259^{\star}$ & 1 & & \\
\hline $\begin{array}{c}\text { 16) } \\
\text { DebtA }\end{array}$ & $-0,1036^{* \star}$ & $-0,2050^{*}$ & $-0,0502$ & $0,1323^{\star \star}$ & $\star-0,2189^{*}$ & $0,1105^{*}$ & *|-0,0762 & $-0,1722^{\star \star}$ & 0,0541 & $-0,1319^{*}$ & $0,1111^{*}$ & $-0,1963^{*}$ & 0,0519 & $-0,1111^{*}$ & $0,8889^{*}$ & 1 & \\
\hline $\begin{array}{c}17) \\
\text { Auditoria }\end{array}$ & $0,1102^{\star \star}$ & 0,0613 & $0,1489^{\star}$ & $-0,0383$ & 0,0174 & $-0,0262$ & 0,4243 * & $0,1715^{\star \star}$ & $0,4783^{*}$ & $0,1389^{\star}$ & $0,0859^{* *}$ & $-0,0859^{\star \star}$ & $-0,0573$ & $-0,1718^{*}$ & $0,1074^{* *}$ & 0,0644 & 1 \\
\hline
\end{tabular}


A correlação é maior para níveis de evidenciação baseados em padrões nacionais, embora o índice de "boas notícias" não seja estatisticamente significativo. 0 tamanho está negativamente correlacionado com os níveis de transparência, excluindo aqueles baseados em IFRS, mas somente significativo quando os GAAPs nacionais são aplicados. As variáveis de lucratividade são positivamente correlacionadas com os níveis de transparência em IFRS e negativamente correlacionadas com o nível de transparência para "boas notícias" em GAAPs nacionais. As razões de alavancagem apresentam correlações negativas estatisticamente significativas com o nível de transparência dos LEs, tanto em IFRS como em GAAPs nacionais. Ter um relatório de auditoria está positivamente correlacionado com os níveis de transparência nos GAAPs nacionais e é mais efetivo para a transparência de “más notícias". 0 desempenho das emissões de GEE é positivamente correlacionado com ROA, ROE e a existência de relatório de auditoria, e negativamente correlacionado com o tamanho e a alavancagem (ver Tabela 2).

As Tabelas 2 a 4 apresentam os resultados para a Equação 1. Destacamos que a adoção de políticas fora do balanço foi considerada equivalente à não evidenciação, pois reduzem o nível de transparência do relatório financeiro. 0 número total de observações diminui devido à introdução no modelo da variável dependente com o atraso de um período como variável explicativa.

Não há evidência nos testes de especificação do modelo de autocorrelação de primeira e segunda ordem nos erros da primeira diferença ( $\mathrm{m} 1$ e m2), mas o modelo 3 na Tabela 4 é motivo de preocupação, pois o valor $p$ está no nível de $10 \%$. Os testes de Hansen sugerem que os instrumentos são válidos, mas na Tabela 4 os modelos 1 e 2 apresentam indícios de sobreidentificação, pois os p-valores de Hansen são 0,734 e 0,803, respectivamente. O número de instrumentos utilizados é elevado para o número de observações, mas como não ultrapassa o número de grupos os modelos permanecem válidos (embora mais fracos). Os testes de Wald apresentam resultados aceitáveis para a significância conjunta das variáveis explicativas, mas não resultados eficientes para as variáveis de controle. Como esperado, as dummies de tempo não são conjuntamente significativas, considerando a consistência necessária nas políticas contábeis para atingir a comparabilidade.

A Tabela 4 sugere que o efeito do desempenho das emissões de GEE no nível de transparência dos relatórios financeiros é negativo e estatisticamente significativo, ou seja, as empresas evidenciam menos políticas contábeis com relação às emissões de GEE quando o desempenho de suas emissões melhora.

Tabela 3. Resultados para o nível de transparência - IFRS e GAAP nacional

\begin{tabular}{|c|c|c|c|c|c|c|}
\hline & \multicolumn{2}{|l|}{ (1) ID } & \multicolumn{2}{|l|}{ (2) ID.LE } & \multicolumn{2}{|l|}{ (3) ID.eGEE } \\
\hline & Coef. & Erro Padrão & Coef. & Erro Padrão & Coef. & Erro Padrão \\
\hline VarDept-1 & $0,2655^{\star *}$ & 0,1043 & $0,3003^{\star}$ & 0,0883 & $0,3123^{\star \star \star}$ & 0,1708 \\
\hline GEEeD & $-0,3643^{\star * *}$ & 0,2059 & $-0,0858$ & 0,0982 & $-0,2263^{\star \star *}$ & 0,1334 \\
\hline Tam & 0,6457 & 0,5301 & $0,4704^{\star \star}$ & 0,2029 & 0,1942 & 0,3439 \\
\hline$R O A$ & 0,0791 & 0,1762 & 0,0404 & 0,0962 & 0,0423 & 0,0839 \\
\hline$R O E$ & $-0,2126$ & 0,1484 & $-0,1297$ & 0,0832 & $-0,0311$ & 0,0893 \\
\hline ROS & $0,5016^{\star \star \star}$ & 0,2589 & 0,2062 & 0,1474 & 0,1292 & 0,1574 \\
\hline DebtE & 0,3523 & 0,3266 & 0,2648 & 0,2040 & 0,1902 & 0,1670 \\
\hline DebtA & $-0,2685$ & 0,3834 & $-0,1793$ & 0,2540 & $-0,1487$ & 0,2081 \\
\hline Auditoria & $2,7846^{\star \star}$ & 1,3441 & $1,6633^{\star \star}$ & 0,6688 & 0,8996 & 0,7069 \\
\hline
\end{tabular}


Tabela 3. Resultados para o nível de transparência - IFRS e GAAP nacional

\begin{tabular}{|c|c|c|c|c|c|c|}
\hline & \multicolumn{2}{|l|}{ (1) ID } & \multicolumn{2}{|l|}{ (2) ID.LE } & \multicolumn{2}{|l|}{ (3) ID.eGEE } \\
\hline & Coef. & Erro Padrão & Coef. & Erro Padrão & Coef. & Erro Padrão \\
\hline _cons & 2,0628 & 1,4832 & -- & -- & $1,7351^{\star \star \star}$ & 0,9506 \\
\hline i.Ano & Yes(1) & & Yes(1) & & Yes(1) & \\
\hline $\begin{array}{l}\text { N.obs / } \\
\text { N.grupos }\end{array}$ & $453 / 85$ & & $453 / 85$ & & $453 / 85$ & \\
\hline$N$ instrumentos & 56 & & 56 & & 54 & \\
\hline Estatística F & $4,19^{\star}$ & & $90,05^{*}$ & & $2,14^{\star}$ & \\
\hline $\mathrm{m}_{1}$ & 0,034 & & 0,018 & & 0,036 & \\
\hline $\mathrm{m} 2$ & 0,882 & & 0,507 & & 0,236 & \\
\hline $\begin{array}{l}\text { Estatística J } \\
\text { Hansen }\end{array}$ & \multicolumn{2}{|c|}{$\begin{array}{l}\operatorname{chi} 2(39)=43,48 \\
\text { Prob }>\text { chi } 2=0,286\end{array}$} & \multicolumn{2}{|c|}{$\begin{array}{l}\operatorname{chi} 2(39)=42,56 \\
\text { Probıchi } 2=0,320\end{array}$} & \multicolumn{2}{|c|}{$\begin{array}{l}\operatorname{chi} 2(37)=42,56 \\
\text { Prob }>\text { chi2 }=0,164\end{array}$} \\
\hline$z 1$ & $\begin{array}{l}\mathrm{F}(2,84)= \\
7,91^{*}\end{array}$ & & $\begin{array}{l}F(2,84)= \\
6,13^{*}\end{array}$ & & $\begin{array}{l}\mathrm{F}(2,84)= \\
5,81^{\star}\end{array}$ & \\
\hline$z 2$ & $\begin{array}{c}F(7,84) \\
=2,50^{\star \star}\end{array}$ & & $\begin{array}{l}F(7,84) \\
=5,05^{*}\end{array}$ & & $\begin{array}{l}F(7,84) \\
=0,87\end{array}$ & \\
\hline$z 3$ & $\begin{array}{l}F(5,84)= \\
0,20\end{array}$ & & $\begin{array}{l}F(6,84)= \\
0,67\end{array}$ & & $\begin{array}{l}F(6,84)= \\
1,16\end{array}$ & \\
\hline
\end{tabular}

A Tabela 4 confirma que o nível de evidenciação reduz quando o desempenho das emissões de GEE aumenta, seja em relação aos LEs ou às emissões. 0 Modelo 2 também sugere que são as entidades maiores que, sendo todas iguais, reduzem o nível de transparência nos relatórios financeiros de seus LEs de acordo com o IFRS.

Tabela 4. Resultados para o nível de evidenciação no IFRS

\begin{tabular}{|c|c|c|c|c|c|c|}
\hline & \multicolumn{2}{|c|}{ (1) IE.IFRS } & \multicolumn{2}{|c|}{ (2) IE.IFRS.LE } & \multicolumn{2}{|c|}{ (3) IE.IFRS.eGEE } \\
\hline & Coef. & Erro Padrão & Coef. & Erro Padrão & Coef. & Erro Padrão \\
\hline VarDep t-1 & 0,1936 & 0,1665 & $0,5889^{*}$ & 0,1786 & 0,3339 & 0,2158 \\
\hline GEEeD & $-0,4338^{\star \star \star}$ & 0,2465 & $-0,2074^{\star}$ & 0,0761 & $-0,1346^{\star * \star}$ & 0,0756 \\
\hline Tam & $-0,0929$ & 0,5329 & $0,3217^{\star \star \star}$ & 0,1836 & $-0,3111$ & 0,2026 \\
\hline ROA & 0,1217 & 0,3077 & 0,0489 & 0,0644 & 0,0414 & 0,0638 \\
\hline ROE & 0,0761 & 0,2393 & 0,0342 & 0,0860 & 0,0646 & 0,0772 \\
\hline ROS & $-0,0952$ & 0,4520 & $-0,0200$ & 0,0769 & $-0,0637$ & 0,0867 \\
\hline DebtE & 0,5209 & 0,4289 & 0,0519 & 0,1625 & 0,1216 & 0,1510 \\
\hline DebtA & $-0,5422^{\star \star \star}$ & 0,3069 & $-0,0220$ & 0,1785 & $-0,0799$ & 0,1611 \\
\hline Auditoria & $-0,8406$ & 1,1412 & 0,2052 & 0,2230 & $-0,4594$ & 0,6386 \\
\hline _cons & -- & & $1,5732^{\star \star \star}$ & 0,8551 & -- & \\
\hline i.Ano & Yes(1) & & $\operatorname{Yes}(1)$ & & Yes & \\
\hline
\end{tabular}


Tabela 4. Resultados para o nível de evidenciação no IFRS

\begin{tabular}{|c|c|c|c|c|c|c|}
\hline & \multicolumn{2}{|c|}{ (1) IE.IFRS } & \multicolumn{2}{|c|}{ (2) IE.IFRS.LE } & \multicolumn{2}{|c|}{ (3) IE.IFRS.eGEE } \\
\hline & Coef. & Erro Padrão & Coef. & Erro Padrão & Coef. & Erro Padrão \\
\hline $\begin{array}{l}\text { N.obs / } \\
\text { N.grupos }\end{array}$ & $296 / 55$ & & $296 / 55$ & & $296 / 55$ & \\
\hline $\mathrm{N}$ instrumentos & 52 & & 36 & & 36 & \\
\hline Estatística F & $34,16^{*}$ & & $3,26^{*}$ & & $21,36^{\star}$ & \\
\hline m1 & 0,076 & & 0,022 & & 0,082 & \\
\hline m2 & 0,476 & & 0,270 & & 0,100 & \\
\hline $\begin{array}{l}\text { Estatística J } \\
\text { Hansen }\end{array}$ & \multicolumn{2}{|c|}{$\begin{array}{c}\operatorname{chi} 2(35)=29,42 \\
\text { Prob>chi2 }=0,734\end{array}$} & \multicolumn{2}{|c|}{$\begin{array}{c}\operatorname{chi} 2(19)=13,67 \\
\text { Prob }>\text { chi2 }=0,803\end{array}$} & \multicolumn{2}{|c|}{$\begin{array}{c}\operatorname{chi} 2(19)=17,62 \\
\text { Prob>chi2 }=0,548\end{array}$} \\
\hline $\mathrm{Z1}$ & $F(2,54)=3,25^{\star *}$ & & $\begin{array}{c}F(2,54)= \\
10,50^{\star}\end{array}$ & & $\begin{array}{c}\mathrm{F}(2,54)= \\
4,50^{\star \star}\end{array}$ & \\
\hline $\mathrm{z} 2$ & $F(7,54)=0,71$ & & $F(7,54)=0,90$ & & $F(7,54)=0,73$ & \\
\hline $\mathrm{z3}$ & $F(6,54)=1,322$ & & $F(6,54)=0,99$ & & $\begin{array}{c}\mathrm{F}(6,54)= \\
2,96^{\star *}\end{array}$ & \\
\hline
\end{tabular}

A Tabela 5 sugere que não há influência estatisticamente significativa do desempenho das emissões de GEE sobre os níveis de transparência nos relatórios financeiros quando estes são baseados em padrões de contabilidade obrigatórios. Foi encontrada uma relação entre o ROA e o ROE e os níveis de transparência das emissões de GEE baseados em contabilidade nacional. Os níveis de transparência nos GAAPs nacionais também são positivamente influenciados pela presença de um relatório de auditor externo.

Tabela 5. Resultados para o nível de evidenciação em GAAPs nacionais

\begin{tabular}{l|c|c|c|c|c|c}
\hline & \multicolumn{2}{|c|}{ (1) GAAPN } & \multicolumn{2}{c}{ (2) GAAPN.LE } & \multicolumn{2}{c}{ (3)GAAPN.eGEE } \\
\hline & Coef. & Erro Padrão & Coef. & Erro Padrão & Coef. & Erro Padrão \\
\hline VarDep t-1 & $0,5888^{\star}$ & 0,1989 & $0,7207^{\star}$ & 0,1826 & $0,7700^{\star}$ & 0,1844 \\
\hline GEEeD & $-0,0725$ & 0,2865 & 0,0168 & 0,1221 & $-0,0688$ & 0,1158 \\
\hline Tam & 0,3506 & 0,5868 & 0,1278 & 0,2745 & 0,1454 & 0,1531 \\
\hline ROA & $0,3478^{\star * \star}$ & 0,1779 & 0,0919 & 0,2243 & $0,3647^{\star \star}$ & 0,1338 \\
\hline ROE & $-0,4269^{\star * *}$ & 0,2170 & $-0,0382$ & 0,2037 & $-0,4509^{\star}$ & 0,1356 \\
\hline ROS & 0,1300 & 0,4087 & 0,1332 & 0,2627 & $-0,0772$ & 0,1424 \\
\hline DebtE & 0,5801 & 0,7682 & 0,2963 & 0,5342 & 0,3178 & 0,2405 \\
\hline DebtA & $-0,3738$ & 0,8781 & $-0,3692$ & 0,5503 & $-0,1754$ & 0,2916 \\
\hline Auditoria & $3,2818^{\star}$ & 1,0177 & $1,3729^{\star \star \star}$ & 0,7905 & $1,1530^{\star}$ & 0,4060 \\
\hline cons & $-0,8177$ & 1,3353 & -- & & $-0,0321$ & 0,9500 \\
\hline i.Ano & Yes(1) & & Yes(1) & & Yes(1) & \\
\hline
\end{tabular}


Tabela 5. Resultados para o nível de evidenciação em GAAPs nacionais

\begin{tabular}{|c|c|c|c|c|c|c|}
\hline & \multicolumn{2}{|c|}{ (1) GAAPN } & \multicolumn{2}{|c|}{ (2) GAAPN.LE } & \multicolumn{2}{|c|}{ (3)GAAPN.eGEE } \\
\hline & Coef. & Erro Padrão & Coef. & Erro Padrão & Coef. & Erro Padrão \\
\hline $\begin{array}{l}\text { N.obs / } \\
\text { N.grupos }\end{array}$ & $157 / 30$ & & $157 / 30$ & & $157 / 30$ & \\
\hline $\mathrm{N}$ instrumentos & 27 & & 27 & & 27 & \\
\hline Estatística F & $63,54^{*}$ & & $132,39^{*}$ & & $63,01^{*}$ & \\
\hline $\mathrm{m}_{1}$ & 0,043 & & 0,106 & & 0,029 & \\
\hline $\mathrm{m} 2$ & 0,187 & & 0,425 & & 0,859 & \\
\hline $\begin{array}{l}\text { Estatística J } \\
\text { Hansen }\end{array}$ & \multicolumn{2}{|c|}{$\begin{array}{c}\operatorname{chi} 2(11)=14,68 \\
\text { Prob }>\text { chi2 }=0,197\end{array}$} & \multicolumn{2}{|c|}{$\begin{array}{c}\text { chi2 }(10)=15,39 \\
\text { Prob>chi2 }=0,118\end{array}$} & \multicolumn{2}{|c|}{$\begin{array}{c}\text { chi2 }(11)=11,74 \\
\text { Prob }>\text { chi2 }=0,384\end{array}$} \\
\hline $\mathrm{Z1}$ & $\begin{array}{c}\mathrm{F}(2,29)= \\
4,60^{\star \star}\end{array}$ & & $F(2,29)=7,79^{\star}$ & & $\begin{array}{c}F(2,29)= \\
14,83^{*}\end{array}$ & \\
\hline $\mathrm{z2}$ & $F(7,29)=7,49^{*}$ & & $F(7,29)=0,89$ & & $\mathrm{~F}(7,29)=6,82^{*}$ & \\
\hline 23 & $F(5,29)=0,80$ & & $F(6,29)=0,52$ & & $F(5,29)=1,32$ & \\
\hline
\end{tabular}

Ao usar um modelo que controla a endogeneidade e considera uma matriz de peso que é heterocedástica, o nível relacional entre a transparência e o desempenho das emissões de GEE é verificado principalmente pela transparência das políticas de emissão de GEE. Concluímos também que uma medida de maior ecoeficiência das emissões de GEE reduz os níveis de transparência em IFRS, ou seja, uma regulamentação contábil que não possui um tratamento contábil específico, mas é reconhecida como de alta qualidade (Barth \& Schipper, 2008).

As evidências também mostraram que o nível de transparência relacionado aos LEs aumenta na presença de uma medida de pior ecoeficiência. Esta é uma evidência de que nos casos em que as emissões de GEE são mais intensas, a integridade dos relatórios financeiros é melhorada com o fornecimento de "boas notícias". Assim, como Luo et al. (2012) e Gallego-Álvarez et al. (2016) argumentaram, através da contabilidade, as empresas podem mostrar algo mais positivo à respeito de suas práticas de emissão de GEE, principalmente em países onde as companhias estão sujeitas à negociação no mercado. A relação entre o desempenho das emissões de GEE e os níveis de transparência nos relatórios financeiros, no entanto, deveria ser mais visível, uma vez que o objetivo de um instrumento de mercado é justamente forçar as empresas a incluírem o 'custo da poluição' em seus relatórios financeiros, e atribuir um valor a ele (Ascui \& Lovell, 2012). A falta de regulamentações do IASB parece estar permitindo que os relatórios financeiros das empresas gerenciem a impressão do desempenho de suas emissões de GEE, relatando mais políticas de LE quando as emissões de GEE são mais intensas.

Por outro lado, a regulação contábil tem sido um fator frequentemente citado como gerador do aumento da evidenciação e garantia das informações necessárias aos stakeholders (Giner-Inchausti, 1997, 2014). Entretanto, não encontramos evidências empíricas que sustentem essa premissa, uma vez que a contabilidade em base as GAAPs nacionais não especifica o efeito do desempenho da empresa em relação as emissões de GEE em seus níveis de transparência. Veith et al. (2009) também discutiram sobre a utilidade da decisão das abordagens brutas, que são a natureza dos relatórios financeiros nacionais prescritos.

No A transparência do desempenho das emissões de GEE questiona a evidenciação financeira que reflete a substância econômica das transações e fornece alguma comparabilidade, pois melhores desempenhos redu- 
zem a evidenciação baseada em IFRS. No entanto, devido ao coeficiente reduzido, concordamos com Freedman e Jaggi (2011) que os resultados não refletem de forma realista a quantidade de emissões de GEE, o que deve afetar os níveis de transparência nos relatórios financeiros. Emissões maiores de GEE devem levar a um aumento na transparência financeira geral, uma questão que não avaliamos nesse estudo. Assim, é necessária uma orientação mais clara aos stakeholders, lhes munindo de informações mais visíveis sobre a exposição ao EU ETS.

\section{CONCLUSÕES}

Este estudo visa fornecer evidências da influência do desempenho das emissões de GEE no nível de transparência dos relatórios financeiros. Raros são os estudos abordando esse tema, visto que os dados sobre o assunto são difíceis de obter e relacionar. Isso é verdadeiro tanto para os dados financeiros, uma vez que o tratamento contábil das LEs e das emissões de GEE requer uma análise das informações financeiras qualitativas, quanto dos dados quantitativos nas cifras de emissões de GEE que são autorrelatadas. Trata-se de uma questão crítica, já que é fundamental analisar a resposta dos relatórios financeiros de todos os agentes poluidores e não apenas dos grandes emissores, porque os mecanismos de mercado têm como objetivo específico tornar os efeitos da poluição observáveis - e a transparência nos relatórios financeiros pode ser a solução para isso. Esta pesquisa destacou o foco na transparência nos relatórios financeiros que devem incluir a economia subjacente das transações do EU ETS e, portanto, refletir a medição ecoeficiente do desempenho das emissões de GEE. Os resultados demonstram que o desempenho das emissões de GEE está negativamente relacionado aos níveis de transparência nos relatórios financeiros baseados em IFRS. Também verificamos que as empresas que adotam IFRS (normas que não apresentam princípios específicos relacionados a LEs e emissões de GEE) optam por evidenciar "boas notícias" relacionadas aos LEs quando o desempenho de suas emissões de GEE reduz. Também sugerimos que os níveis de transparência nos relatórios financeiros são influenciados de forma diferente pelo desempenho das emissões de GEE quando a base de apresentação das demonstrações financeiras incorpora um tratamento contábil específico, caso do GAAPs. No entanto, não conseguimos obter evidências empíricas a esse respeito, o que levanta dúvidas se a abordagem bruta adotada pelos reguladores nacionais está internalizando os custos das emissões de GEE conforme pretendia o EU ETS. Como resultado, essa linha de estudo precisa ser continuada.

Deve-se atentar ainda para as limitações inerentes ao este estudo. 0 uso da análise de conteúdo pode resultar em viés, uma vez que em alguns casos torna-se necessário elaborar julgamentos subjetivos, o que mostrou-se verdade ao avaliarmos os níveis de transparência e procedermos a referência cruzada do arquivo das emissões verificadas com a entidade relatora. Reconhecemos também que o uso de todas as empresas listadas no PNA com demonstrações financeiras anuais disponíveis pode incluir informações que carecem de materialidade, o que aumenta a adoção de políticas de não evidenciação e não reconhecimento.

Apesar das limitações acima, o desempenho das emissões de GEE e os requisitos regulatórios parecem ser a única maneira de obter relatórios financeiros mais transparentes e melhorar a evidenciação da poluição. Isso evidencia as discrepâncias entre a aplicação de uma norma com princípios específicos e as transações do EU ETS, que é de interesse dos responsáveis pela elaboração de relatórios financeiros como reguladores, gestores e contadores. É também de interesse para aqueles que têm curiosidade na integridade dos relatórios financeiros, o que fundamenta a importância da economia das transações. 


\section{REFERÊNCIAS}

Abrell, J., Ndoye, A., Zachmann, G. (2011). Assessing the impact of the EU ETS using firm level data. Bruegel Working Paper, No. 2011/08, Bruegel, Brussels. Recuperado de https://www. econstor.eu/bitstream/10419/77988/1/664523234.pdf

Adams, C. A., Coutts, A., \& Harte, G. (1995). Corporate equal opportunities (non-) disclosure. British Accounting Review, 27(June,), 87-108. doi: 10.1006/bare.1994.0005

Al-Tuwaijri, S. A., Christensen, T. E., \& Hughes, K. E. (2004). The relations among environmental disclosure, environmental performance, and economic performance: A simultaneous equations approach. Accounting, Organizations and Society, 29(5-6), 447-471. doi: 10.1016/S0361-3682(03)00032-1

Arellano, M., \& Bond, S. (1991). Some tests of specification for panel data: Monte Carlo evidence and an application to employment equations. The Review of Economic Studies, 58(2), 277. doi: 10.2307/2297968

Arellano, M., \& Bover, O. (1995). Another look at the instrumental variable estimation of error-components models. Journal of Econometrics, 68(1), 29-51. doi: 10.1016/03044076(94)01642-D

Ascui, F., \& Lovell, H. (2012, November). Carbon accounting and the construction of competence. Journal of Cleaner Production, 36, 48-59. doi: 10.1016/j.jclepro.2011.12.015

Ayaz, H. (2017). Analysis of carbon emission accounting practices of leading carbon emitting European Union companies. Athens Journal of Business \& Economics, 3(4), 463-486. doi: 10.30958/ajbe.3.4.5

Barth, M. E., \& Schipper, K. (2008). Financial reporting transparency. Journal of Accounting, Auditing \& Finan, 23(2), 173-190. doi: 10.1177/0148558X0802300203

Bebbington, J., \& Larrinaga-González, C. (2008). Carbon trading: Accounting and reporting issues. European Accounting Review, 17(4), 697-717. doi: 10.1080/09638180802489162

Black, C. M. (2013). Accounting for carbon emission allowances in the European Union: In search of consistency. Accounting in Europe, 10(2), 223-239. doi: 10.1080/17449480.2013.834730

Burritt, R. L., Schaltegger, S., \& Zvezdov, D. (2011). Carbon management accounting: Explaining practice in leading German companies. Australian Accounting Review, 21(1), 8098. doi: 10.1111/j.1835-2561.2010.00121.x

Busch, T., \& Hoffmann, V. H. (2011). How hot is your bottom line? Linking carbon and financial performance. Business \& Society, 5o(2), 233-265. doi: 10.1177/0007650311398780

Cho, C. H., \& Patten, D. M. (2007). The role of environmental disclosures as tools of legitimacy: A research note. Accounting, Organizations and Society, 32(7-8), 639-647. doi: 10.1016/j. aos.2006.09.009
Clarkson, P. M., Li, Y., Pinnuck, M., \& Richardson, G. D. (2015). The valuation relevance of greenhouse gas emissions under the European Union carbon emissions trading scheme. European Accounting Review, 24(3), 551-580. doi: 10.1080/09638180.2014.927782

Clarkson, P. M., Li, Y., Richardson, G. D., \& Vasvari, F. P. (2008). Revisiting the relation between environmental performance and environmental disclosure: An empirical analysis. Accounting, Organizations and Society, 33(4-5), 303-327. doi:10.1016/j.aos.2007.05.003

Connors, E., \& Gao, L. S. (2011). Corporate environmental performance, disclosure and leverage: An integrated approach. International Review of Accounting, Banking and Finance, 3(3), 1-32. Recuperado de https://corporate-sustainability.org/ wp-content/uploads/Connors-Gao.pdf.

Criado-Jiménez, I., Fernández-Chulián, M., Husillos-Carqués, F. J., \& Larrinaga-González, C. (2008). Compliance with mandatory environmental reporting in financial statements: The case of Spain (2001-2003). Journal of Business Ethics, 79(3), 245-262. doi:10.1007/s10551-007-9375-7

Cuesta, C. F., Moneva, J. M., \& Larrinaga, C. (2006). Derechos de emisión de gases efecto invernadero: Registro, valoración e información. Partida Doble, (182), 88-97. Recuperado de http://www.cambioclimatico.gov.co/jsp/loader.jsf?IServicio $=$ Publicaciones\& $\mid$ Tipo $=$ publicaciones\&lFuncion=loadCon tenidoPublicacion\&id $=1305$

Dechow, P., Ge, W., \& Schrand, C. (2010). Understanding earnings quality: A review of the proxies, their determinants and their consequences. Journal of Accounting and Economics, 50(2-3), 344-401. doi:10.1016/j.jacceco.2010.09.001

Ehrenfeld, J. R. (2005). Eco-efficiency: Philosophy, theory, and tools. Journal of Industrial Ecology, 9(4), 6-8. doi:10.1162/108819805775248070

Elfrink, J., \& Ellison, M. (2009). Accounting for emission allowances: An issue in need of standards. The CPA Journal, 79(2), 30. Recuperado de http://proquest. umi.com/pqdweb?did=1644702761\&Fmt=7\&clien$\mathrm{tld}=20901 \& \mathrm{RQT}=309 \& \mathrm{VName}=\mathrm{PQD}$

Elo, S. \& Kyngas, H. (2008). The qualitative content analysis process. Journal of Advanced Nursing, 62(1), 107-115. doi: 10.1111/j.1365-2648.2007.04569.x

Ertimur, Y., Francis, J., Gonzales, A., \& Schipper, K. (2017). Financial reporting for pollution reduction programs. Recuperado de https://ssrn.com/abstract=2969339

European Financial Reporting Advisory Group. (2012). Emissions trading schemes: Draft comment paper. Recuperado de https://www.efrag.org/Activities/264/EFRAG-Emission-Trading-Schemes 
European Financial Reporting Advisory Group. (2013). Emission trading schemes: Feedback statement on comment paper. Recuperado de https://www.efrag.org/Activities/264/EFRAG Emission-Trading-Schemes

Freedman, M., \& Jaggi, B. (2011). Global warming disclosures: Impact of Kyoto protocol across countries. Journal of International Financial Management and Accounting, 22(1), 46-90. doi:10.1111/j.1467-646X.2010.01045.X

Gallego-Álvarez, I., Martínez-Ferrero, J., \& Cuadrado-Ballesteros, B. (2016). Accounting treatment for carbon emission rights. Systems, 4(1), 12. doi: 10.3390/systems4010012

Giner-Inchausti, B. (1997). The influence of company characteristics and accounting regulation on information disclosed by Spanish firms. European Accounting Review, 6(1), 45-68. doi:10.1080/096381897336863

Giner-Inchausti, B. (2007). La contabilidad de los derechos de emisión: Una perspectiva internacional. Revista Espanola de Financiacion y Contabilidad, 36(133), 175-193. doi: 10.1080/02102412.2007.10779619

Giner-Inchausti, B. (2014). Accounting for emission trading schemes: A still open debate. Social and Environmental Accountability Journal, 34(1), 45-51. doi: $10.1080 / 0969160 X .2014 .885670$

Haupt, M. \& Ismer, R. (2013). The EU Emissions Trading System under IFRS - Towards a 'True and Fair View'. Accounting in Europe, 10(1), 71-97. doi: 10.1080/17449480.2013.772726

Jaggi, B., Allini, A., Macchioni, R., \& Zagaria, C. (2018). The factors motivating voluntary disclosure of carbon information: Evidence based on Italian listed companies. Organization \& Environment, 31(2), 178-202. doi:10.1177/1086026617705282

Labra, R., \& Torrecillas, C. (2014). Guia CERO datos de panel: Un enfoque práctico. UAM-Accenture Working Papers (\#2014/16). Recuperado de https://www.catedrauam-innova.com/documents/Working\%2opapers/WP2014_16 Guia\%20CERO\%20 para\%20datos\%20de\%2opanel_Un\%2oenfoque\%2opractico.pdf

Larrinaga, C., Carrasco, F., Correa, C., Llena, F., \& Moneva, J. (2002). Accountability and accounting regulation: The case of the Spanish environmental disclosure standard. European Accounting Review, 11(4), 723-740. doi:10.1080/0963818022000001000

Leung, D. Y. \& Chung, B.P.M. (2019). Content analysis: Using critical realism to extend Its utility. In P. Liamputtong (Ed.), Handbook of research methods in health social sciences (pp. 827-841). Singapore: Springer. doi: 10.1007/978-981-10-52514_102

Liu, Y., Zhou, X., Yang, J. \& Hoepner, A. G. F. (2017). Corporate Carbon Emissions and Financial Performance: Does Carbon Disclosure Mediate the Relationship in the UK? SSRN Electronic Journal. doi:10.2139/ssrn.2941123
Llena, F., Moneva, J. M., \& Hernandez, B. (2007, January). Environmental disclosures and compulsory accounting standards: The case of Spanish annual reports. Business Strategy and the Environment, 16, 50-63. doi:10.1002/bse.466

Lovell, H., Sales de Aguiar, T., Bebbington, J., \& Larrinaga-Gonzalez, C. (2010). Accounting for Carbon. Research Report 122 - ACCA. London (UK): The Association of Chartered Certified Accountants. Recuperado de: https://www.accaglobal.com/ content/dam/acca/global/PDF-technical/climate-change/rr122-001.pdf

Lovell, H., Bebbington, J., Larrinaga, C., \& Sales de Aguiar, T. (2013). Putting carbon markets into practice: A case study of financial accounting in Europe. Environment and Planning C: Government and Policy, 31(4), 741-757. doi: 10.1068/c1275

Luo, L., Lan, Y. C., \& Tang, Q. (2012). Corporate incentives to disclose carbon information: Evidence from the CDP Global 500 Report. Journal of International Financial Manage ment and Accounting, 23(2), 93-120. doi: 10.1111/j.1467646X.2012.01055.X

MacKenzie, D. (2009). Making things the same: Gasses, emission rights and the politics of carbon markets. Accounting, Organizations and Society, 34(3-4), 440-455. doi: 10.1016/j. aos.2008.02.004

Mateos, A. I., \& Bilbao, I. (2007). Planificación contable y derechos de emission de gases efecto invernadero. Revista Universo Contábil, 3(3), 101-122. Recuperado de http://www.redalyc. org/service/redalyc/downloadPdf/1170/117016548008/1

Matsumura, E. M., Prakash, R., \& Vera-Muñoz, S. C. (2014). Firm-value effects of carbon emissions and carbon disclosures. Accounting Review, 89(2), 695-724. doi: 10.2308/accr50629

Milanés-Montero, P., \& Pérez-Calderón, E. (2011). Corporate environmental disclosure and legitimacy theory: An Europe perspective. Environmental Engineering and Management Journal, 10(12), 1883-1891. doi:10.30638/eemj.2011.252

Ortas, E., Gallego-Álvarez, I., \& Álvarez-Etxeberria, I. (2015). Financial factors influencing the quality of corporate social responsibility and environmental management disclosure: A quantile regression approach. Corporate Social Responsibility and Environmental Management, 22(6), 362-380. doi:10.1002/csr.1351

Patten, D. M. (2002). The relation between environmental performance and environmental disclosure: A research note. Accounting, Organizations and Society, 27, 763-773. doi: 10.1016/S0361-3682(02)00028-4

Pindado, J., \& Requejo, I. (2015). Panel data: A methodology for model specification and testing. (3rd ed.) C. Cooper, K. Paudyal (Eds.), Wiley encyclopedia of management, Chapter 4, John Wiley \& Sons. doi: 10.1002/9781118785317.weomo 40013 
Prado-Lorenzo, J.-M., Rodríguez-Domínguez, L., Gallego-Álvarez, I., \& García-Sánchez, I.-M. (2009). Factors influencing the disclosure of greenhouse gas emissions in companies world-wide. Management Decision, 47(7), 1133-1157. doi: $10.1108 / 00251740910978340$

PricewaterhouseCoopers \& International Emissions Trading Association (2007). Trouble-Entry accounting -Revisited. Uncertainty in accounting for the EU Emissions Trading Scheme and Certified Emission Reductions. London: PricewaterhouseCoopers. Recuperado de http://www.ieta.org/index. php?option $=$ com_content $\&$ view $=$ article $\& i d=329 \% 3$ Atrou ble-entry-accounting---revisited $*$ $\&$ catid $=27 \% 3$ Aarchived-reports \& Itemid $=93$

Qian, W., \& Schaltegger, S. (2017). Revisiting carbon disclosure and performance: Legitimacy and management views. British Accounting Review, 49(4), 365-379. doi:10.1016/j. bar.2017.05.005

Qiu, Y., Shaukat, A., \& Tharyan, R. (2016). Environmental and social disclosures: Link with corporate financial performance. British Accounting Review, 48(1), 102-116. doi:10.1016/j. bar.2014.10.007

Ragan, J. M., \& Stagliano, A. J. (2007). Cap and trade allowance accounting: A divergence between theory and practice. Journal of Business \& Economics Research, 5(11), 47-58. doi: 10.19030/jber.v5i11.2602

Roberts, R. W. (1992). Determinants of corporate social responsibility disclosure: An application of stakeholder theory. Accounting, Organizations and Society, 17(6), 595-612. doi: 10.1016/0361-3682(92)90015-K
Schiemann, F., \& Sakhel, A. (2019). Carbon disclosure, contextual factors, and information asymmetry: The case of physical risk reporting. European Accounting Review, 28(4), 791-818. doi: $10.1080 / 09638180.2018 .1534600$

Steenkamp, N., Rahman, A., \& Kashyap, V. (2011, 5-7 Decembe). Recognition, measurement and disclosure of carbon emission allowances under the EU ETS: An exploratory study. Paper presented at the CSEAR 2011 Australasian Conference, University of Tasmania, Australia. Recuperado de http://www.massey. edu/massey/fms/Colleges/College $\% 200 f \% 20$ Business/ School\%200f\%20Accountancy/ARA\%202012/Kashyap_Accounting\%2ofor.pdf

Veith, S., Zimmermann, J., \& Werner, J. R. (2009). Competing accounting treatments for emission rights: A capital market perspective, Available at SSRN 1323810. 605-613. Recuperado de https://papers.ssrn.com/sol3/papers.cfm?abstract $\mathrm{id}=1323810$

Warwick, P., \& Ng, C. (2012). The "cost" of climate change: How carbon emissions allowances are accounted for amongst European Union companies. Australian Accounting Review, 22(1), 54-67. doi: 10.1111/j.1835-2561.2011.00158.x

Windmeijer, F. (2005). A finite sample correction for the variance of linear efficient two-step GMM estimators. Journal of Econometrics, 126(1), 25-51. doi: 10.1016/j.jeconom.2004.02.005

Yu, H. (2013). The EU ETS and firm profits: An ex-post analysis of Swedish energy firms. Environmental Economics, 4(3), 5971. Recuperado de https://www.businessperspectives.org/ images/pdf/applications/publishing/templates/article/ assets/5426/ee_2013_03_Yu.pdf

\section{CONTRIBUIÇÃO DE AUTORIA}

Patricia Milanés-Montero, Esteban Pérez-Calderón e Ana Isabel Dias trabalharam na conceituação e abordagem teórico-metodológica. A revisão teórica foi realizada por Esteban Pérez-Calderón e Patricia Milanés-Montero. A coleta de dados foi coordenada por Ana Isabel Dias. A análise dos dados foi realizada por Ana Isabel Dias, Patricia Milanés-Montero e pelo Esteban Pérez-Calderón. Patricia Milanés-Montero, Esteban Pérez-Calderón e Ana Isabel Dias trabalharam juntos na redação e revisão final do manuscrito. 